\title{
Zigbee-110 Applications on Wireless Two Robot Humanoid Communications for Mobile Phone
}

\author{
Rummi Santi Rama Sirait ${ }^{1}$, Amalia Zulaikha ${ }^{2}$ \\ \{rummi.sirait@budiluhur.ac.id ${ }^{1}$ \} \\ Faculty of Technic Technical Electronic Program Universitas Budi Luhur, Jakarta, Indonesia ${ }^{1,2}$
}

\begin{abstract}
This study aims to realize and analyze the performance of communication system between 2 pieces of dancing robot using Zigbee-110 on humanoid robot. With this wireless communication system synchronization of movement in both robots will be achieved. The test results show the robot to move dancing through Zigbee-110 communication from robot $\mathrm{A}$ to robot $\mathrm{B}$ and robot $\mathrm{B}$ to robot $\mathrm{A}$ can successfully receive and send the appropriate data. The robot can communicate from robot A to robot B with a predetermined distance of $100 \mathrm{~cm}$ and robot $B$ to robot A with a distance of $75 \mathrm{~cm}$ in accordance with the provisions of the contest KRSI (Indonesian Art Robot Contest) 2015. Test results also show the greater the data received then the value of throughput is also greater and the greater the time required to communicate between the two robots. The thermal noise value affects the emergence of communication failure between the two robots.
\end{abstract}

Keywords: Wireless communication, ZigBee-110, robot humanoid, software roboplus.

\section{Introduction}

Humanoid robot is a robot formed based on the appearance of the human body [1]. In general, humanoid robots have body parts such as head, body, two arms and two legs. Humanoid robots are generally made to perform primitive behaviour from humans. One of the human capabilities that a humanoid robot wants to adopt is dancing.

In research Sulistyo (2015) has created a communication system between two humanoid robots that dance. With this communication is expected to improve the movement system between the two robots in performing the synchronization of dance movements following the movement of human dance in general [2]. The development of robotics, especially the development of humanoid robot is now very much, but no one has applied wireless communication technology between the two robots. So with this wireless communication synchronization movement on both robots can be achieved.

This study discusses the performance analysis of communication systems of two humanoid robots on Zig-110. This system uses the method of half duplex communication data sent using wireless. Implementation of this system is to reduce the use of cable in communication data sent periodically, the data sent with a predetermined time when the robot is active then read the data and send it and the robot will move [3].

The name ZigBee stands for two words: zigzag and bee, which means the bees are flying with a change of direction [4]. Technically speaking, however, ZigBee is a specification for high-level communication protocols related to Wireless Personal Area Networks (WPANs) 
[5]. ZigBee devices are often used to connect other devices with a wireless system. ZigBee technology is able to manage its own network and able to manage the exchange of data. ZigBee network is also widely applied to embedded systems (embedded applications), such as the control of industrial equipment wirelessly, wireless sensors and others.

\section{System Designing}

Designing a zigbee-110 application on communication 2 Robots for dancing and running are controlled by the CM-530 controller. The reason for using Zigbee as a wireless controller is because it has several advantages, such as concise (does not require cable installation and flexibility between space), cost-effective and easy software configuration [6]. The discussion includes hardware design consisting of mechanical and electronic robot systems, and software design, ie system flowchart design and program flowchart to be embedded in CM-530 controllers.

\subsection{System Block Diagram}

The block diagram of the transmitter and receiver system is shown in Figure. 1 and 2.

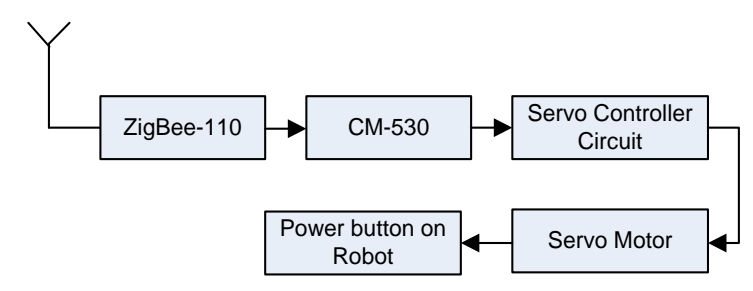

Fig. 1. Transmitter block diagram.

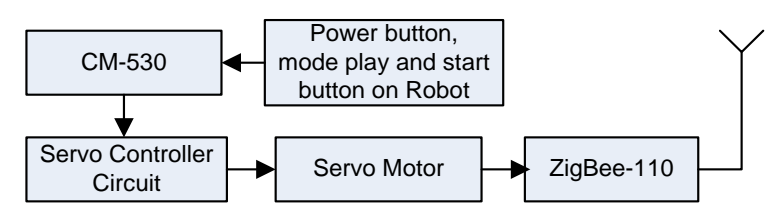

Fig. 2. Receiver block diagram.

Push Button on the robot will send the analog signal data to the CM-530 controller that can be processed and send data to the servo controller circuit so as to cause dancing movement. Via Zigbee-110 on robot 1 will transmit digital signal data to Zigbee-110 robot 2 receiver and can be processed by CM-530. The data from CM-530 is then transmitted to the servo controller circuit which will drive the servo motor, resulting in dance movements and running on the humanoid robot according to the sent command. 
The CM-530 controller is a microcontroller that controls and processes the input and output data of the actuator. From the input side, there is a switch On/ Off is in use to turn on and off the power on the robot.

\subsection{Mechanical Design}

The design of robotic mechanical systems is done by modifying the standard mechanical Atype bioloid robot, with the shape shown in Figure 3.

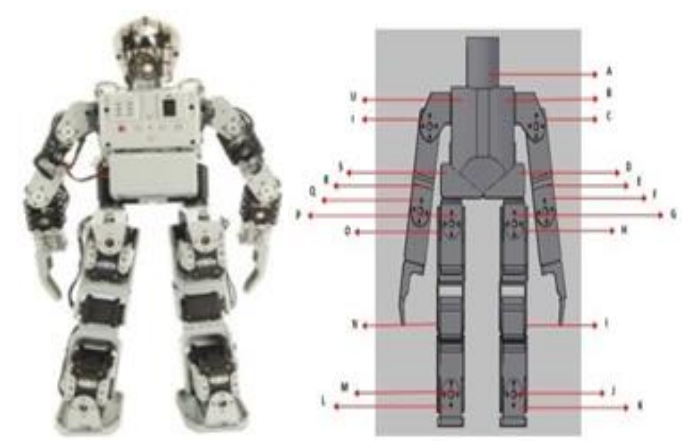

Fig. 3. Bioloid Premium Robot Type A before being modified.

Description of dots Joints Freedom:

A: Joints to the Head

B \& U: Joints on Shoulders

C \& T: Upper Arm Sleeve

D \& S: Joints on Hips

E \& R: Joints on Arms under pitch

F \& Q: Joints on Arms Under Roll

G \& P: Joints in the Thigh Roll

$\mathrm{H} \&$ O: Joints on the Thigh Pitch

I \& N: Joints on the knee

$\mathrm{J} \& \mathrm{M}$ : Joints on the Pitch wrist

K \& L: Joints on Wrist Roll

The design of robotic mechanical systems is done after modifying the standard mechanical Atype bioloid robot. Modifications made consist of: 1 . The addition of three servo motor 12 volts on the head. Used so that the robot head can move left and right and move up and down. 2. Added 12 volt servo motor on right and left wrist. Used for the palm of the hand to move. 3. The addition of frames on the robot knees using Bioloid Premium frame. Used for robots to increase in height where the size is adjusted with the rules KRSI (Indonesian Art Robot Contest) in 2015. 4. The shape of the robot palm is modified by using aluminum material. Used to resemble human hands. 5. The shape of the foot of the robot is modified by using aluminum material. The robot's foot is made to minimize the falling. The physical shape of the robot after it is modified as shown in Figure 4. 

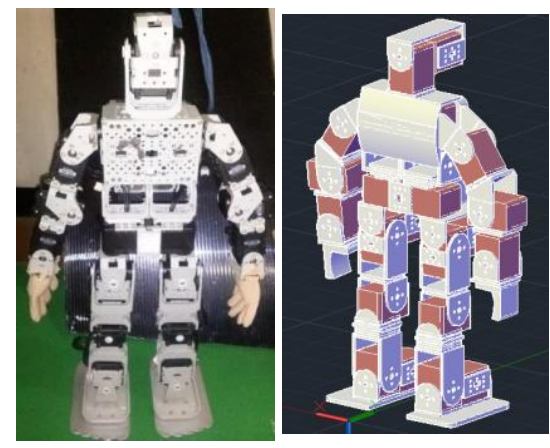

Fig. 4. Bioloid Premium Robot Type A after modification.

\subsection{The Whole System Block}

The whole system set is shown in figure 5 .

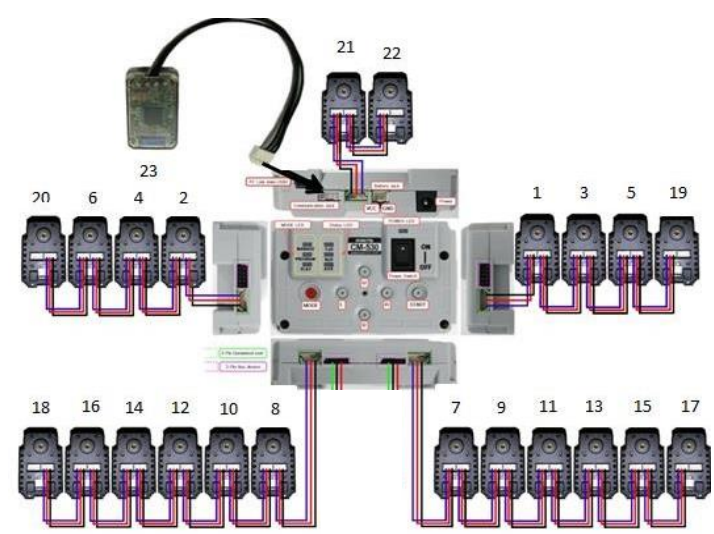

Fig. 5. The whole system set.

Description of the whole system is shown in Table 1.

Table 1. Description of the whole system.

\begin{tabular}{ll}
\hline & \multicolumn{1}{c}{ Aspect } \\
\hline 1 & Servo left shoulder \\
2 & Servo right shoulder \\
3 & Servo hip left \\
4 & Right hip servo \\
5 & Servo upper left arm \\
6 & Servo upper arm right \\
7 & Servo left forearm \\
8 & Servo right forearm \\
9 & Servo groin left roll \\
\hline
\end{tabular}




\begin{tabular}{ll}
\hline 10 & Servo groin right roll \\
11 & Servo groin left pitch \\
12 & Servo groin right pitch \\
13 & Servo left knee \\
14 & Right knee servo \\
15 & Servo left ankle roll \\
16 & Servo right ankle roll \\
17 & Servo left pitch ankle \\
18 & Servo right pitch ankle \\
19 & Left wrist servo \\
20 & Right wrist servo \\
21 & Servo head look right left \\
22 & Servo head up nod down \\
23 & The zigbee-110 module \\
24 & Gyroscope Sensor \\
\hline
\end{tabular}

\subsection{ZigBee-110 Communication Module}

ZIG-110 is a communication module that can be used to build a simple PAN (Personal Area Network) for communication between devices. MCU (Micro Controller Unit) and ZigBee IC have been integrated in ZIG-110 Set. The ZIG-110 Set module operates at a $2.4 \mathrm{GHz}$ frequency to communicate through the UART interface. Equipped with packaging for protection and cable with 4 pin connector for connection with other compatible devices.

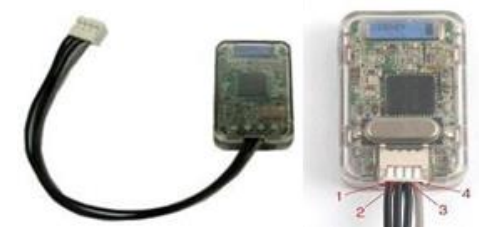

Fig. 6. Overall system set.

\subsection{Motor Servo Dinamyxel AX-12A}

Servo motors serve to regulate the movement of robots. Servo motors used in this robot is a servo motor type AX-12. AX-12 is one type of precision servo motor. AX-12 has gear arrangement and circuit controller contained in 1 package. This controller cicuit serves as the brain of each servo that works for feedback to improve motor rotation, besides this controller is useful for communication with CM-510. With the circuit control of each servo, it can be seen the variables contained in the servo. Starting from the large turning angle, rotational speed, and large torque to the temperature on the servo motor. In addition, the control circuit on the AX-12 serves as a safety motor 27 that is used and also serves as a communication between the server with a master control that is CM-510.

\subsection{System Flow Diagram}

System flow diagram of Robotic humanoid communication robot design with the zigbee-110 communication module shown in Figures 7 and 8. 


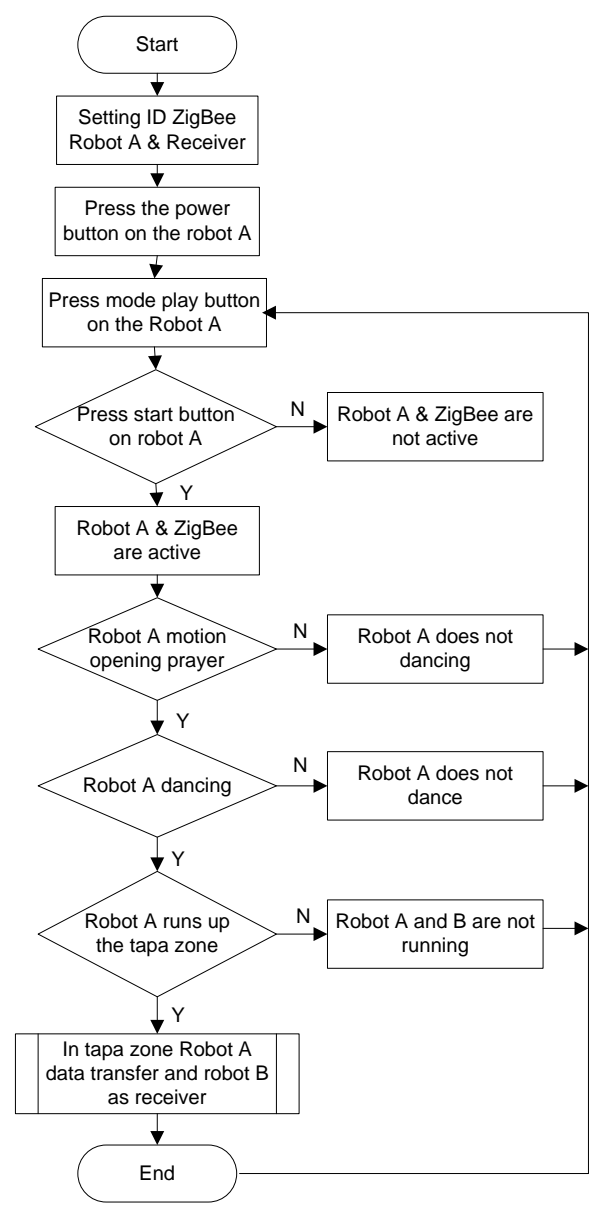

Fig. 7. Flowchart Robot A.

In the flowchart of wireless communication robot $\mathrm{A}$, robot $\mathrm{B}$ data transfer and robot $\mathrm{A}$ as receiver. If robot $\mathrm{A}$ and robot $\mathrm{B}$ are not running, both robots are reset. In the main programming flow diagram of wireless communication robot $\mathrm{B}$ there are two robot communication program, robot $\mathrm{B}$ data transfer and robot $\mathrm{A}$ as receiver. 


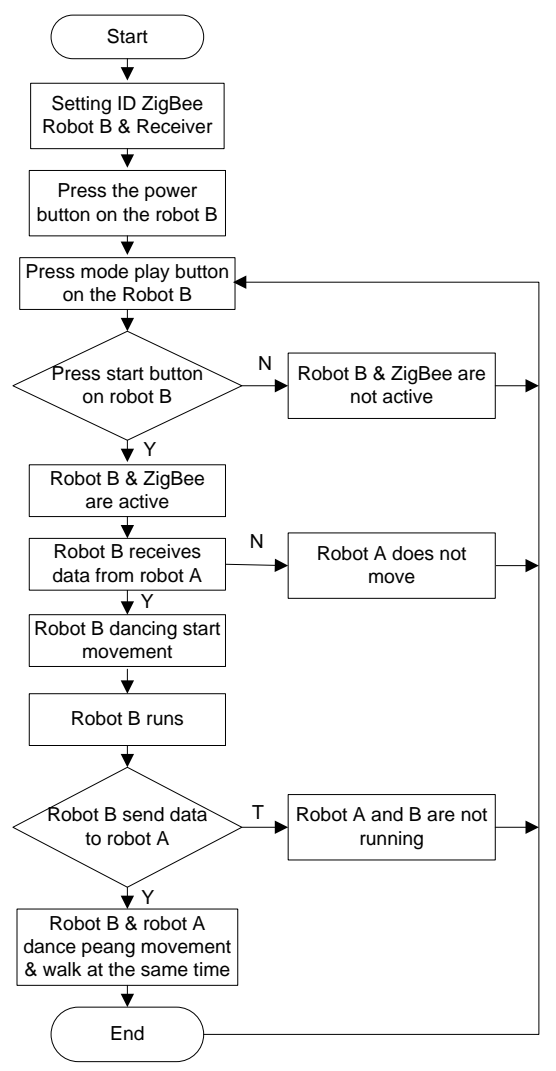

Fig. 8. Robot flow diagram B.

\section{Testing and Analysis}

\subsection{Dynamixel servo motor testing}

Testing of servo motors is done to know the relation between widths of PWM pulse given to rotation angle servo motor. The equipment used in this test is AX-12A servo motor, CM-530 controller, and laptop-operated roboplus manager software.

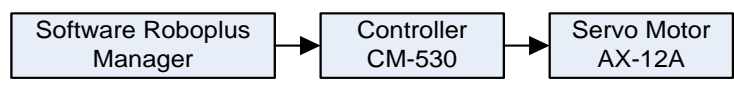

Fig. 9. Block diagram of servo motor servo AX-12A. 


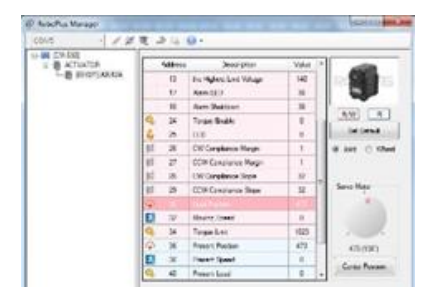

Fig. 10. display the position of the servo motor.

\subsection{Testing Zigbee-110 Communication Robot A to Robot B}

In the design of communication systems of two robots in this study using two modules Zigbee-110 that connected in robot A and robot B.

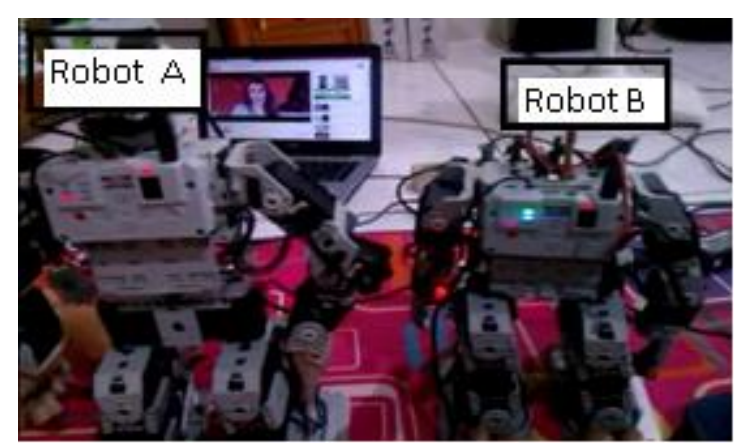

Fig. 11. Communication robot A to robot B.

The Zigbee-110 module test is performed to know that each Zigbee-110 module can send and receive data properly. Figure 8 shows the led on the robot $B$ receives the communication data from robot A. The zigbee-110 test starts from the robotic zone A. A communicates up to the start zone of robot $\mathrm{B}$, zigbee testing of the middle zones of the robot $\mathrm{B}$ to the robot $\mathrm{A}$ in the tapa zone. Testing aims to determine the communication from robot $\mathrm{A}$ to robot $\mathrm{B}$ to perform the motion of dance.

Table 2. Throughput of robot A to robot B.

\begin{tabular}{ccccc}
\hline $\begin{array}{c}\text { Data } \\
\text { received }\end{array}$ & $\begin{array}{c}\text { Distance } \\
(\mathrm{cm})\end{array}$ & $\begin{array}{c}\text { Duration } \\
(\text { sekon })\end{array}$ & Throughput Thermal Noise \\
\hline 65535 & 100 & 14,87 & 4407,20 & $1,76 \times 10^{-17}$ \\
16384 & 100 & 26,43 & 619,90 & $2,48 \times 10^{-18}$ \\
4096 & 100 & 14,68 & 279,02 & $1,12 \times 10^{-18}$ \\
1024 & 100 & 25,04 & 40,89 & $1,64 \times 10^{-19}$ \\
256 & 100 & 14,50 & 17,66 & $7,07 \times 10^{-20}$ \\
64 & 100 & 10,27 & 10,27 & $4,11 \times 10^{-20}$ \\
16 & 100 & 4,16 & 4,16 & $2,48 \times 10^{-20}$ \\
\hline
\end{tabular}


The test results from each data received robot communication $\mathrm{A}$ and robot $\mathrm{B}$ on throughput and thermal noise, the greater the data received the greater the throuhput value with a small thermal noise then the communication has a good performance as shown in table 2 and figure 12.

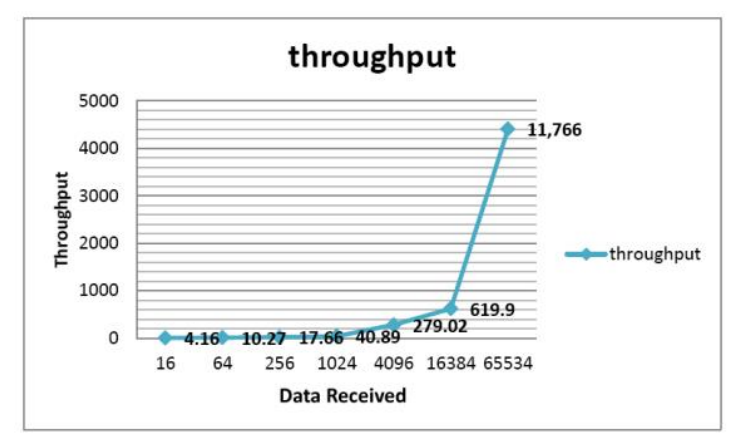

Fig. 12. Graphs Throughput of robot A to robot B.

From the graph of throughput with the received data it appears that the greater the data received, then the value of throughput is also large then the communication network has a good performance and also for time graph with the data received, the greater the data received the greater the time required for communicate between the two robots, as shown in figure 13.

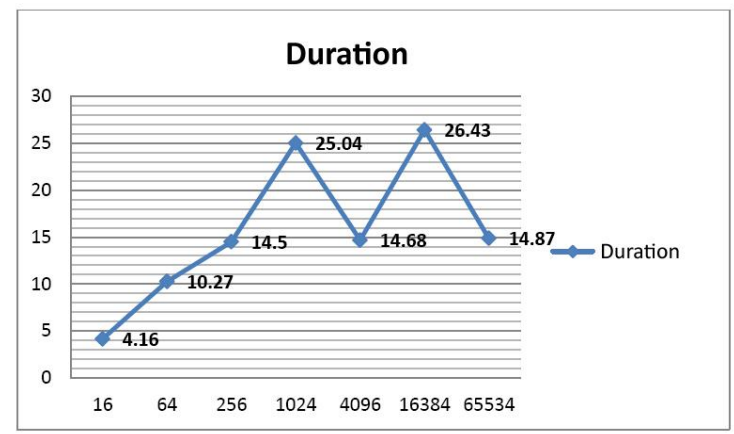

Fig. 13. Time frame graph of robot A to robot B.

\subsection{Testing Zigbee-110 robot $B$ communication to robot $A$}

The Zigbee-110 module test is performed to know that each Zigbee-110 module can send and receive data well, From Figure 11 showing the led on the robot communication B sends the data and robot A receives the data. 


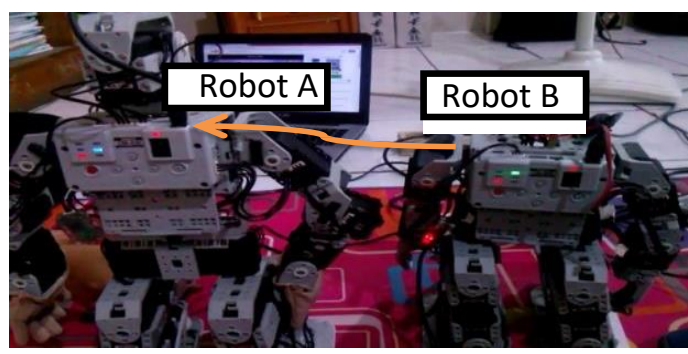

Fig. 14. Communication robot $B$ to robot $A$.

The test results of each data received robot communication B and robot A on throughput and thermal noise, the greater the data received the greater the throughputvalue with small thermal noise then the communication has a good performance as shown in table 3 and figure 15 .

Table 3. Robot B throughput B to robot A.

\begin{tabular}{cccc}
\hline $\begin{array}{c}\text { Data } \\
\text { received }\end{array}$ & $\begin{array}{c}\text { Distance } \\
(\mathrm{cm})\end{array}$ & Throughput & Thermal Noise \\
\hline 32768 & 13,23 & 8989.85 & $9,92 \times 10^{-18}$ \\
8192 & 21,50 & 381.023 & $1,53 \times 10^{-18}$ \\
2048 & 12,94 & 158.27 & $6,34 \times 10^{-19}$ \\
512 & 21,42 & 23.903 & $9,57 \times 10^{-20}$ \\
128 & 12,78 & 10.02 & $4,01 \times 10^{-20}$ \\
32 & 2,01 & 15.893 & $6,36 \times 10^{-20}$ \\
10 & 12,49 & 0.80064 & $3,20 \times 10^{-21}$ \\
\hline
\end{tabular}

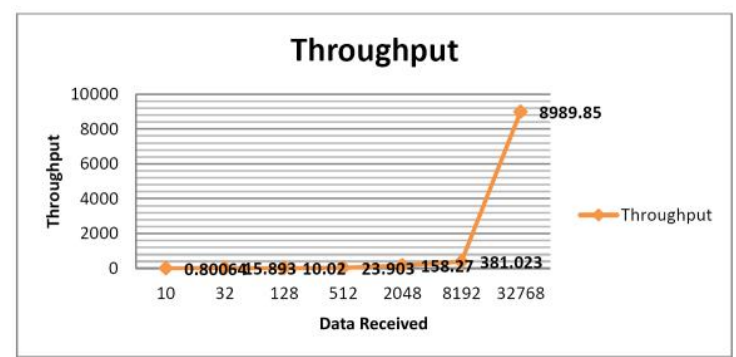

Fig. 15. Graph of throughput of robot B to robot A

From the picture throughput graph to the data the greater the data received then the throughput value is also greater than the communication network has a good performance and also the time graph with the data received, the greater the data received the greater the time required, as shown in the picture 15 and table 3 . 


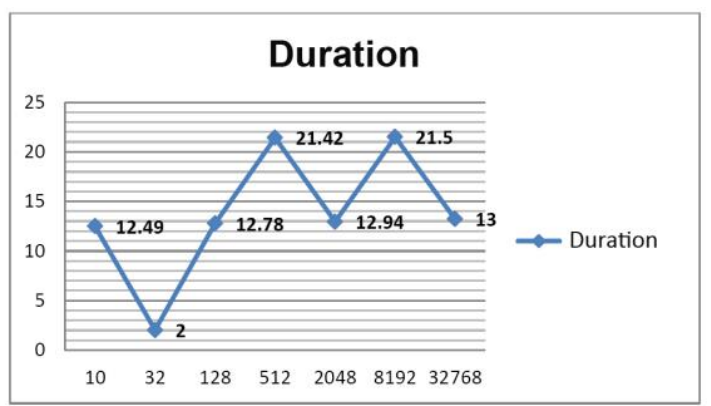

Fig. 16. Time frame graph of robot $B$ to robot $A$.

\section{Conclusions}

From the design and testing system that has been done, can be drawn conclusion as follows:

1. For each pattern of movement done robot, data and position of each servo motor actuator angle can be known.

2. Wireless communication model zigbee-110 on robot A and robot B can receive the same data in accordance with the data transmitted.

3. From testing robot $\mathrm{A}$ to robot $\mathrm{B}$ and robot $\mathrm{B}$ to robot $\mathrm{A}$, the greater the data received then the value of throughput is also greater.

4. The greater the data received the greater the time required to communicate between the two robots, and the value of thermal noise affects the emergence of communication failure between two robots.

5. A robot can send data to robot $\mathrm{B}$ and robot $\mathrm{B}$ can send data also to robot $\mathrm{A}$ and can perform the dance moves as desired.

\section{References}

[1]A. R. A. Besari, D. K. Basuki, G. P. R. H. Milzam, N. E. Khomariah, D. R. Wati, and T. Suliswanto, "Desain Perancangan dan Algoritma Robot Tari Humanoid ERISA versi 1.0," Indones. Symp. Robot Soccer Compet. 2013, pp. 131-136, 2013.

[2]E. Sulistyo, "Sistem Komunikasi Robot Humanoid Dalam Aplikasi Robot Penari," Semin. Nas. Sains dan Teknol. 2015 Fak. Tek. Univ. Muhammadiyah Jakarta, pp. 1-5, 2015.

[3]R. Syam and J. Hair, "Desain Kerjasama Mobile Manipulator Robot," J.Oto.Ktrl.Inst, vol. 8, no. 2, pp. 125-137, 2016.

[4]Yuliza, "Komunikasi Antar Robot Menggunakan RF Xbee dan Arduino Microcontroller," IncomTech, J. Telekomun. dan Komput., vol. 4, pp. 53-68, 2013.

[5]P. Widiantoro, M. Abdurohman, and N. A. Suwastika, "Penerapan Zigbee Untuk Komunikasi pada Prototipe Robot Pelayan Berbasis Mikrokontroler," in e-Proceeding of Engineering, 2015, vol. 2, no. 1, pp. 1229-1236.

[6]B. Rahmani and H. Aprilianto, "Model Kendali Multi Kontroler untuk Robot Humanoid dengan 19 Derajat Kebebasan,” in Konferensi Nasional Sistem \& Informatika 2015, 2015, pp. 186-191. 